\title{
Consensus Statement of the European Urology Association and the European Urogynaecological Association on the Use of Implanted Materials for Treating Pelvic Organ Prolapse and Stress Urinary Incontinence
}

\begin{abstract}
Christopher R. Chapple ${ }^{a, *}$, Francisco Cruz $^{b, c}$, Xavier Deffieux ${ }^{d}$, Alfredo L. Milani ${ }^{e}$, Salvador Arlandis ${ }^{f}$, Walter Artibani ${ }^{g}$, Ricarda M. Bauer ${ }^{h}$, Fiona Burkhard $^{i}$, Linda Cardozo $^{j}$, David Castro-Diaz ${ }^{k}$, Jean Nicolas Cornu ${ }^{l}$, Jan Deprest ${ }^{m}$, Alfons Gunnemann ${ }^{n}$, Maria Gyhagen ${ }^{o}$, John Heesakkers ${ }^{p}$, Heinz Koelbl ${ }^{q}$, Sheila MacNeil ${ }^{r}$, Gert Naumann ${ }^{s}$, Jan-Paul W.R. Roovers ${ }^{t}$, Stefano Salvatore ${ }^{u}$, Karl-Dietrich Sievert ${ }^{v}$, Tufan Tarcan ${ }^{w}$, Frank Van der Aa ${ }^{x}$, Francesco Montorsi $^{y}$, Manfred Wirth ${ }^{z}$, Mohamed Abdel-Fattah ${ }^{\text {aa }}$

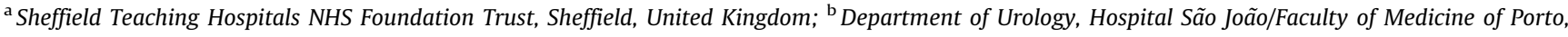
Porto, Portugal; ' ${ }^{\mathrm{C}}$ I3S Institute for Health, Porto, Portugal; ${ }^{\mathrm{d}}$ Department of Gynaecologic Surgery, Antoine Béclère Hospital, Paris South University, Clamart, France; ${ }^{\mathrm{e}}$ Department of Obstetrics \& Gynaecology, Reinier de Graaf Hospital, Delft, The Netherlands; ${ }^{\mathrm{f}}$ Department of Urology, La Fe University and Polytechnic Hospital, Valencia, Spain; ${ }^{\mathrm{g}}$ Department of Urology, Azienda Ospedaliero Universitaria di Verona, Verona, Italy; ${ }^{\mathrm{h}}$ Department of Urology, LudwigMaximilians-University Muenchen, Klinikum Großhadern, Muenchen, Germany; ${ }^{\mathrm{i}}$ Department of Urology, University Hospital Bern, Bern, Switzerland; ${ }^{\mathrm{j}}$ Department of Urogynaecology, King's College Hospital, London, United Kingdom; ${ }^{\mathrm{k}}$ Department of Urology, Hospital Universitario de Canarias, Universidad de La Laguna, Tenerife, Canary Islands, Spain; ' ${ }^{1}$ Department of Urology, Rouen University Hospital and University of Rouen, Rouen Cedex, France; ${ }^{\mathrm{m}}$ Department of Obstetrics and Gynaecology, University Hospitals Leuven, Leuven, Belgium; ${ }^{\mathrm{n}}$ Klinikum Lippe Urologische Klinik, Akademisches Lehrkrankenhaus der Georg-August-Universität Göttingen, Germany; ${ }^{\circ}$ Department of Obstetrics and Gynecology, Södra Älvsborgs Hospital, Borås, Sahlgrenska Academy at Gothenburg University, Gothenburg, Sweden; ${ }^{\mathrm{p}}$ Radboud UMC, Nijmegen, The Netherlands; ${ }^{\mathrm{q}}$ Department of General Gynaecology and Gynaecologic Oncology, Medical University of Vienna, Vienna, Austria; ${ }^{\mathrm{r}}$ Department of Tissue Engineering, University of Sheffield, Sheffield, United Kingdom; ${ }^{\mathrm{s}}$ Department of Obstetrics and Gynaecology, Helios-Klinikum, Erfurt, Germany; ${ }^{\mathrm{t}}$ Department of Obstetrics and Gynaecology, Academic Medical

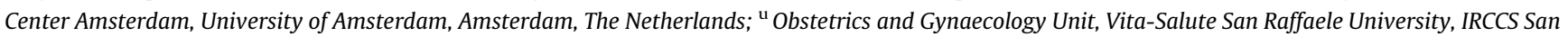
Raffaele Hospital, Milan, Italy; ${ }^{\mathrm{v}}$ Paracelsus Medical University, Salzburg, Austria; ${ }^{\mathrm{w}}$ Department of Urology, Marmara University School of Medicine, Istanbul, Turkey; ${ }^{x}$ Department of Urology, University Hospitals Leuven, KU Leuven, Leuven, Belgium; ${ }^{y}$ Department of Urology, Vita Salute San Raffaele University,

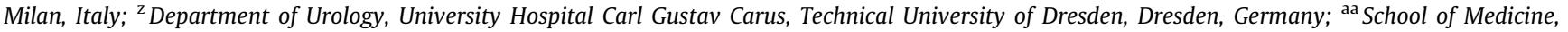
Medical Sciences and Nutrition, University of Aberdeen, Scotland, United Kingdom
\end{abstract}

Article info

Article history:

Accepted March 30, 2017

Associate Editor:

James Catto

\begin{abstract}
Context: Surgical nonautologous meshes have been used for several decades to repair abdominal wall herniae. Implantable materials have been adopted for the treatment of female and male stress urinary incontinence (SUI) and female pelvic organ prolapse (POP).

Objective: A consensus review of existing data based on published meta-analyses and reviews.

Evidence acquisition: This document summarises the deliberations of a consensus group meeting convened by the European Association of Urology (EAU) and the European Urogynecological Association, to explore the current evidence relating to
* Corresponding author. Sheffield Teaching Hospitals NHS Foundation Trust, Sheffield, United Kingdom. Tel. +44 114279 7841; Fax: +44 1142797841.

E-mail address: c.r.chapple@shef.ac.uk (C.R. Chapple).
\end{abstract}

http://dx.doi.org/10.1016/j.eururo.2017.03.048

0302-2838/C 2017 European Association of Urology. Published by Elsevier B.V. All rights reserved. 


\section{Keywords:}

Mesh

Stress urinary incontinence

Pelvic organ prolapse

Consensus statement the use of polypropylene (PP) materials used for the treatment of SUI and POP, with reference to the 2016 EAU guidelines (European Association of Urology 2016), the European Commission's SCENIHR report on the use of surgical meshes (SCENIHR 2015), other available high-quality evidence, guidelines, and national recommendations.

Evidence synthesis: Current data suggest that the use of nonautologous durable materials in surgery has well-established benefits but significant risks, which are specific to the condition and location they are used for. Various graft-related complications have been described-such as infection, chronic pain including dyspareunia, exposure in the vagina, shrinkage, erosion into other organs of xenografts, synthetic PP tapes (used in SUI), and meshes (used in POP)-which differ from the complications seen with abdominal herniae. Conclusions: When considering surgery for SUI, it is essential to evaluate the available options, which may include synthetic midurethral slings (MUSs) using PP tapes, bulking agents, colposuspension, and autologous sling surgery. The use of synthetic MUSs for surgical treatment of SUI in both male and female patients has good efficacy and acceptable morbidity. Synthetic mesh for POP should be used only in complex cases with recurrent prolapse in the same compartment and restricted to those surgeons with appropriate training who are working in multidisciplinary referral centres.

Patient summary: Synthetic slings can be safely used in the surgical treatment of stress incontinence in both male and female patients. Patients need to be aware of the alternative therapy and potential risks and complications of this therapy. Synthetic mesh for treating prolapse should be used only in complex cases with recurrent prolapse in specialist referral centres.

(C) 2017 European Association of Urology. Published by Elsevier B.V. All rights reserved.

\section{Introduction}

If lifestyle interventions, pelvic floor muscle training (PFMT), pessary treatment, and drug therapy for stress urinary incontinence (SUI) and pelvic organ prolapse (POP) are unsuccessful, the surgeon may have to decide whether to use a surgical approach. For SUI and POP surgery, biological grafts derived from either xenograft or allograft materials and autologous tissue are alternatives to synthetic tapes/meshes. Current evidence would not support the use of nonautologous biological materials, whether of human or animal origin. Nonabsorbable synthetic polypropylene (PP) tapes/meshes have widely been used and other materials to a lesser extent. Aspects that need to be carefully considered are the filamentous structure (mono- or multifilament) and its pore size, surface area, textile properties, and type of polymer used. Postimplantation changes linked to biomechanics and host response are likely to influence the clinical outcomes, but implantation techniques, surgeon experience, and patient risk factors are equally important contributing factors.

Patient stratification based on careful assessment according to contemporary guidelines is essential, as are adequate identification of the patient's goals and expectations, counselling of patients, collaborative decision making, and appropriate surgeon experience and expertise. The group highlights that the ultimate aim of any surgical treatment for non-life-threatening conditions is to improve the patient's quality of life.

In view of current controversies relating to the use of implanted materials for SUI and POP, and the lack of clear guidelines for the use of biomaterials, the European Association of Urology (EAU) and European Urogynecological Association (EUGA) convened this expert group to discuss the evidence relating to current practice in this area of functional urology and urogynaecology. The conclusions from the group are presented in this consensus statement.

\section{The clinical problem}

Pelvic floor dysfunction is a major health problem for many women, and SUI affects an estimated one in three women and POP affects an estimated one in nine women [1]. It is strongly linked to childbearing [2], obesity, and advancing age, and it is not surprising that there has been an increase in the lifetime risk that a woman will undergo a surgery for SUI and POP, from $11 \%$ in 1997 to $19-20 \%$ at present [3,4]. A Norwegian study [5] reported the percentage of patients with SUI to be approximately half of all women with incontinence, with the remainder characterised as urgency (11\%) and mixed incontinence (36\%). In a large observational cohort study, anatomical prolapse stage 2 or higher was observed in more than one of two women $12 \mathrm{yr}$ after first delivery [6]. In another study, $24 \%$ of prolapses protruded beyond the hymen, a point where most women become symptomatic [7]. The lifetime risk for parous women to undergo at least one surgical treatment for either SUI or POP is 1:10 [8]. With surgical repair using native tissue there is a failure rate for primary repair of POP of approximately $17-20 \%$ in $10 \mathrm{yr}$ [9]. This has resulted in the adoption of mesh-augmented prolapse repair.

POP is less commonly seen in male patients, and SUI is usually seen only as a consequence of surgery on the prostate-usually after radical prostatectomy for prostate cancer, where percentages up to $31 \%$ are reported [10], or intervention albeit far less commonly for benign prostatic obstruction.

\section{Treatment of SUI in women}

PFMT/physiotherapy is usually considered to be an effective treatment for mild to moderate SUI in the short to medium term and certainly is more effective than no treatment. One large multicentre randomised controlled trial (RCT) compared PFMT/physiotherapy and synthetic midurethral-sling 
(MUS) surgery in women with SUI and showed a significantly higher patient-reported success rate in women who underwent MUS surgery at 1-yr follow-up (91\% vs 65\%; 95\% confidence interval $[\mathrm{CI}]$ 18.1-34.5). Similarly, the objective cure rates were higher in the MUS group. Interestingly, the favourable results with MUS pertained in a per-protocol analysis, which showed that women who crossed over to the surgery group had outcomes similar to those of women initially assigned to surgery and that both these groups had outcomes superior to those of women who underwent PFMT only [11]. In addition, PFMT requires persistence and some form of maintenance programme to preserve the curative effect. Such an effort may lead a substantial number of women to abandon the PFMT programme and seek alternative forms of treatment that may provide more rapid cure [11].

Open retropubic colposuspension was commonly used until $15 \mathrm{yr}$ ago and has been a widely evaluated surgical technique for SUI. Open retropubic colposuspension is associated with high rates of objective and subjective cure, especially in the long term [12]. After $5 \mathrm{yr}$, approximately $70 \%$ of women remained "dry". Laparoscopic colposuspension is associated with similar cure rates of SUI when compared with open colposuspension if undertaken in the same way, but with a lower risk of complications and a shorter hospital stay [13]. Colposuspension, however, involves significant repositioning of the anterior pelvic compartment and is associated with a significant incidence of secondary POP of the posterior pelvic compartment [14]. A most recent systematic review and meta-analysis showed that synthetic MUSs were associated with significantly higher cure rates compared with colposuspension in both patient-reported outcomes (any definition of continence: $81.8 \%$ vs $73.6 \%$, odds ratio [OR]: 0.59 ; $95 \% \mathrm{CI}: 0.45-0.79$; $p=0.0003$ ) and objective continence rates (negative stress test: $79.7 \%$ vs $67.8 \%$, OR: $0.51 ; 95 \% \mathrm{CI}: 0.34-0.76 ; p=0.001$ ). Notably, stratifying the colposuspension outcomes according to the surgical approach (open vs laparoscopic), the differences in favour of synthetic MUS pertained [15].

Several techniques have been described using needle suspension; however, this is now rarely used due to poor long-term durability as well as complications associated with the synthetic cuffs used [16].

The pubovaginal and autologous fascial sling techniques have been used for many years and are usually performed via an abdominal route. The autologous sling is made of a strip of tissue from the abdominal rectus fascia or fascia lata. Autologous fascial slings are associated with similar cure rates of SUI for women when compared with open colposuspension, but with a higher risk of postoperative complications (bladder outlet obstruction, need for selfcatheterisation, etc.) $[17,18]$. In recent years, a shorter sling (sling on a string) has been used based on a needle suspension technique, in a more minimally invasive manner, placed loosely and midurethrally [19]. The updated systematic review and meta-analysis showed that, on the whole, synthetic MUSs and autologous slings were associated with similar effectiveness and similar prevalence of complications. However, there was a clear trend towards lower reoperation rates and lower postoperative storage symptoms with synthetic MUSs [15].

MUS using synthetic PP tape is the recommended method of surgical approach for the correction of SUI in the 2016 EAU guidelines. Both retropubic and transobturator (TO) approaches are well-established standard MUSs within clinical practice. The 2015 Cochrane review [20] and the recent SCENIHR report [21] concluded that synthetic MUSs are the most extensively researched surgical treatment for SUI, with over 200 published clinical trials establishing its effectiveness and good safety profile. Long-term outcomes for the TO approach have since been published [22-24]. In recent years, some surgeons used single-incision mini-slings in clinical practice; however, no long-term data exist on their efficacy $[21,25]$. One systematic review have shown that excluding TVT-Secur, there was no evidence of significant differences in patient-reported and objective cure compared with MUSs at 18-mo followup, while they were associated with more favourable recovery [26].

Urethral balloons and injectables are not recommended as first-line therapy for SUI [25]. Bulking agents are associated with lower cure rates of SUI when compared with colposuspension or autologous fascial slings [27]. There are insufficient data concerning periurethral stem cells (autologous myoblasts, muscle-derived stem cells, and autologous fibroblasts) injection that is supposed to treat intrinsic sphincteric deficiency [28].

The artificial urinary sphincter (AUS) [29] in women has not yet been widely used or evaluated in an RCT. This technique is not recommended as a first-line surgical treatment for SUI [25,30-32].

\section{Treatment of POP in women}

Spontaneous progression of symptoms and/or anatomical status in women with POP is common, but a large prospective cohort study concluded that only a small proportion of women with symptomatic POP show progression within $5 \mathrm{yr}[33,34]$.

Whilst local vaginal oestrogen therapy can provide good symptomatic relief for urogenital atrophy, there is no evidence that it is beneficial in correcting POP [35].

PFMT, with or without pessary use, should be considered as treatment for stage 1 or 2 POP (there is evidence that PFMT does not work well for stage 3 or 4 POP), but the training needs proper instruction from a specialist in women's health physiotherapy and close follow-up to be effective. PFMT is associated with some improvement in symptoms in the short term (12 mo) for early-stage POP and a marginal decrease in International Continence Society POP quantification system stage [36]. Lifestyle advice to patients such as weight loss and improving general physical fitness is recommended, to attempt to improve symptoms and prevent progression of POP. However, irrespective of initial PFMT, many patients will require surgical intervention. Pessary use is an effective and patient-reported satisfactory treatment albeit with side effects, but the discontinuation rate is high at long-term follow-up [37]. 
Anterior colporrhaphy is performed through an anterior vaginal wall incision and plication of the vaginal tissues in the midline using absorbable sutures. Recurrence rates are high when using anatomic outcome criteria. However, when contemporary "functional" outcome measures are used, with appropriate selection of patients, better results can be obtained [38,39]. The technique of transvaginal rectocele repair allows correction of fascial defects, by separating the rectum and vaginal epithelium [40].

The relatively high recurrence and reoperation rates (30\%), especially after traditional (anterior/posterior) repair, and the high success rates for using mesh in abdominal hernia surgery and SUI surgery led to the quick adoption of transvaginal mesh (TVM)-augmented pelvic floor repair procedures. However, concerns have been raised on the safety of TVM, with serious adverse events being reported. The Food and Drug Administration issued a series of statements on the safety of TVM and finally reclassified TVM in prolapse repair into high-risk devices. The PROSPECT multicentre RCT comparing traditional repair versus synthetic mesh and biological grafts in $>1000$ women and with 24-mo follow-up has recently been published [41]. The results showed no benefit from TVM- or biological graftaugmented pelvic floor repair over the traditional repair in both patient-reported outcomes (at $2 \mathrm{yr}$ ) and objective outcomes (at $1 \mathrm{yr}$ ). In addition, there were no significant differences in serious adverse events, dyspareunia rates, recurrence of prolapsed, or reoperation rates for prolapse. However, $12 \%$ of women in the synthetic mesh group underwent reoperations for management of mesh complications. The authors concluded that in absence of any benefit, synthetic mesh-augmented pelvic floor repair as a primary prolapse procedure may pose unnecessary risks; however, they emphasised the importance of long-term follow-up.

Depending on the patient's individual characteristics, the treatment of a uterine/apical prolapse can entail hysteropexy or colpopexy, or hysterectomy with colpopexy [40]. A variety of procedures exist for vault/uterine suspension for women who are deemed fit for surgery; the two most commonly performed procedures are sacrocolpopexy (open/laparoscopic/robotic) and vaginal sacrospinous fixation (SSF). Other procedures include uterosacral vault suspension and the rarely performed Infracoccygeal vaginal sling (IVS).

Abdominal sacrocolpopexy (ASC) is the most durable operation for advanced POP and serves as the criterion standard with which other operations are compared [40]. ASC involves attaching the vaginal apex to the sacral anterior longitudinal ligament reinforced with a graft, usually synthetic mesh $[42,43]$. The Cochrane review showed that compared with SSF, ASC was associated with significantly fewer women being aware of prolapse or requiring repeat surgery and lower rates of postoperative dyspareunia. Long-term outcomes ( $7 \mathrm{yr}$ ) for the well-designed CARE study reported that nearly one-third of women who underwent ASC met their composite definition of failure. The reoperation rate was $16.7 \%$-almost divided equally into one-third for POP, one-third for SUI, and one-third for mesh-related complications.

Colpocleisis (LeFort colpocleisis, colpectomy) is offered to women with POP, who no longer wish to preserve vaginal coital function. The technique consists of vaginal closure + /- colpectomy. Colpocleisis is associated with high success rates, and low recurrence and complication rates, especially after the age of $80 \mathrm{yr}$ [44-46].

Uterine suspension using nonabsorbable sutures has widely been reported by laparotomy or laparoscopy [47]. The use of strips of skin [48] or fascia lata [49] for uterine and bladder suspension has also been described.

Abdominal uterosacral ligament suspension (colpopexy) consists of suspending the vaginal apex (mainly following concomitant hysterectomy) to the uterosacral ligaments, using nonabsorbable or absorbable sutures, laparoscopically $[50,51]$ or by laparotomy [52-54]. It has been reported that abdominal uterosacral ligament colpopexy (with concomitant hysterectomy) was associated with an increased risk of recurrence (6.2 times higher) when compared with ASC and hysterectomy [55]. The long-term anatomical and functional outcomes, and the exact number and nature of complications, are, at this moment, not well studied for these procedures.

\subsection{Consensus view}

In addition to a consensus discussion, careful consideration of the European Commission's Scientific Committee on Emerging and Newly Identified Health Risks report on the safety of surgical meshes used in urogynaecological surgery [21] was undertaken, and this consensus follows on from and supports the deliberations of that panel.

A number of different types of potential materials can be used in POP and SUI mesh surgery, which include the following categories:

1. Allografts (eg, cadaveric fascia and dura mater)

2. Xenografts (eg, porcine and bovine)

3. Autografts (eg, fascia lata and rectus fascia)

4. Synthetic meshes (nonabsorbable, eg, PP mesh as well as absorbable)

It is important to differentiate between the use of synthetic MUSs for the treatment of SUI and large surface areas of mesh for treating POP.

Based on the work with mesh in anterior abdominal hernia repair, a classification of synthetic mesh material has been reported [56]. A type 1 macroporous PP mesh has been proposed as the most appropriate material for vaginal implantation for SUI and POP, the principal characteristics being that it should be monofilament with the pore size being $>75$ microns. It is evident that a number of materials had been evaluated in managing anterior abdominal wall hernias until this classification was formulated. Careful consideration needs to be given to the design and weave of synthetic mesh materials, as these can have a significant effect on efficacy and safety. 
It is our consensus that types 2 and 3 (microporous, $<10$ microns, mono- and multifilament) and type 4 (submicronic and monofilament) are not appropriate for use in this clinical context.

When considering risk factors for mesh materials, it is important to consider the following important issues:

1. Overall surface area of the material used (which is greater for POP than for SUI)

2. Mesh design (eg, physical characteristics of the mesh, size of the pore as a predisposing factor to infection-in particular with a pore size of $<75$ microns)

3. Material (biocompatibility, long-term stability, flexibility, elasticity, etc.)

The factors influencing the surgical outcomes are as follows:

1. Indication for which the material is used

2. Overall surface area of the material used (lower overall surface area for SUI than for POP)

3. Material characteristics (polymer used, physical characteristics of the mesh, size of the pores, surface area, biocompatibility, long-term stability, compliance)

4. Route of implantation (eg, vaginal or transabdominal)

5. Patient characteristics (eg, somatic inflammatory disease, obesity, smoking)

6. Associated procedures (eg, hysterectomy)

7. Surgeon experience

There is a lack of both preclinical and real-life practice clinical data. Whilst there are randomised controlled studies, the majority are limited in terms of the number of recruited individuals and duration of follow-up, and they do not evaluate differences in product design.

It is clear that:

1. The risk of use of a mesh increases with its surface area and, thereby, its increasing density.

2. In this context, a clear distinction should be drawn between the tape used for synthetic MUSs and the larger amount of mesh used to treat POP. A significantly greater amount of mesh is implanted in patients with POP than in those with SUI.

3. Surgeons should be adequately experienced in the management of SUI and POP, and should have all the therapeutic options available (or be able to refer to colleagues if required). Patients should be appropriately assessed and counselled prior to making a decision to undergo surgery, regarding the experience of the surgeon and results of the proposed technique.

4. There is higher mesh-associated morbidity when treating patients with POP as compared with using synthetic MUSs for SUI.

5. The efficacy and use of synthetic MUSs for SUI is evident, and it can be recommended for use in clinical practice, whilst acknowledging the limitations of existing longterm data and under-reporting of other studies relating to long-term follow-up in real-life clinical practice.
6. Synthetic MUSs are now the most widely used surgical approach for SUI with well-established success rates and safety profile. The efficacy is higher than colposuspension and comparable with autologous slings, but with lesser morbidity compared with colposuspension. Morbidity is uncommon, but may occur either at the time of implantation (eg, bladder perforation or vascular/bowel injury) or subsequently (eg, tape exposure, pain, or erosion into the urinary tract). Existing data do not allow reliable quantification of tape-specific long-term risks, but it may be $4 \%$ [57].

7. Vaginally implanted mesh for POP is associated with increased risks. Its use should be restricted to the special group of patients defined according to established evidence-based clinical guidelines or in the context of ethics committee-approved clinical research. Its use should also be restricted to expert individuals working in specialised departments. Whilst the risk associated with the transabdominal insertion of mesh for POP is considered more acceptable, its use should also be restricted to specialist practice.

8. Based on the available scientific evidence, the SCENIHR [21] recommends the following:

(a) Implantation of any mesh for the treatment of POP via the vaginal route should only be considered in complex cases, in particular after failed primary repair surgery.

(b) Owing to increased risks associated with the use of synthetic mesh for POP repair via a transvaginal route, this option should only be used when other surgical procedures have already failed or are expected to fail.

(c) The amount of mesh should be limited for all procedures where possible. However, there is a need for further improvement in the composition and design of synthetic mesh, in particular for POP surgery.

(d) A certification system for surgeons should be introduced based on existing international guidelines and established in cooperation with the relevant European Surgical Associations.

(e) Appropriate patient selection and counselling are of paramount importance for the optimal outcome for all surgical procedures, particularly for the indications discussed. This should be based on the results of further clinical evidence, which should be collected in a systematic fashion for all these devices.

9. Therapy should only be instituted in accordance with EAU guidelines and with full informed consent of all patients.

\section{Treatment of SUI in men}

Physiotherapy is considered to be better than no treatment at all, as it is suggested that patients should not undergo surgery for stress SUI for at least $6 \mathrm{mo}$ and preferably not before $1 \mathrm{yr}$ after initial surgery. In addition, it is important to exclude the presence of an anastomotic stenosis and bladder dysfunction in cases of postradical prostatectomy prior to considering any corrective surgery. 
Urethral injections of bulking agents have been advocated, but no existing evidence indicates that bulking agents cure postprostatectomy incontinence. There is weak evidence that bulking agents can offer temporary improvement of incontinence and in quality of life in men with postprostatectomy incontinence [25].

The AUS is considered to be the standard of care for men with moderate to severe SUI; however, the quantity and level of evidence for effectiveness is low with no welldesigned prospective RCTs. Nonrandomised cohort studies suggest that primary AUS implantation is effective for cure and improvement of SUI in men, but may be less effective for men who have had pelvic radiotherapy and associated with higher morbidity such as erosion.

\subsection{Male synthetic mesh sling}

Slings tapes are positioned under the bulbar urethra, and fixed by a retropubic or TO approach. Possible risks include voiding dysfunction, device erosion, and chronic pain [25], although these are significantly lower in comparison with women.

There is no evidence that adjustability of male sling systems offers an additional benefit over other types of male slings, but may require multiple adjustments [25]. Possible complications include voiding dysfunction, device erosion, chronic pain (more often compared with fixed male synthetic mesh slings), infection, and explantation due to infection and chronic pain.

\subsection{Consensus view}

Synthetic male slings are accepted as an effective therapy, with expert opinion suggesting that they are most appropriately directed at the treatment of men with milder forms of stress incontinence, with AUS implantation being more appropriately used in patients with all degrees of severity, but more so in more severely symptomatic patients. There is an absence of adequate randomised controlled studies looking at surgical treatment, and further comments on efficacy await the results of such work, such as the MASTER trial in the UK which has so far recruited over 270 men of the 360 required [58]. Synthetic slings using existing material are reported to be associated with postoperative discomfort in up to $10 \%$ of patients with a low incidence of infection and mesh exposure. This is considered to be an acceptable therapy in contemporary practice. Patients should be adequately counselled about the safety and efficacy of therapeutic options. In addition, proper patient selection is necessary to achieve good results.

\section{Overall conclusions}

It is clear that the use of synthetic MUSs for surgical treatment of SUI in both male and female patients has good efficacy and acceptable morbidity. However, synthetic mesh for POP should be used only in complex cases with recurrent prolapse in the same compartment and restricted to those surgeons with appropriate training who are working in multidisciplinary referral centres. Patients should be adequately informed regarding the potential success rates and mesh-related adverse events compared with nonmesh alternatives, and should be engaged in the decision-making process.

We recommend the following as essential for the future:

1. Design implants specifically for their application, rather than extrapolate from indications in abdominal wall repair.

2. Establish accurate and complete databases registering the numerator and denominator, patient profile and surgical experience.

3. Establish long-term assessment in high-quality RCTs and mandatory postmarketing registries.

4. Research new materials that should be introduced into clinical practice according to a cautious and rigorous process [59].

5. Follow the evidence-based EAU and EUGA guidelines $[25,60]$.

6. Support and register the specialist training of surgeons in urology and urogynaecology.

7. Encourage multidisciplinary team working.

8. Develop appropriate information for patients.

9. Collaborate with patient advocacy groups.

10. Encourage premarketing safety and efficacy data before using a product in routine clinical practice.

11. Establish reference centres for reinterventions (complicated cases).

12. Use condition-specific patient-reported outcome measures wherever possible.

Author contributions: Christopher Ronald Chapple had full access to all the data in the study and takes responsibility for the integrity of the data and the accuracy of the data analysis.

Study concept and design: None.

Acquisition of data: None.

Analysis and interpretation of data: None.

Drafting of the manuscript: Chapple, Cruz, Deffieux, Milani, Arlandis, Artibani, Bauer, Burkhard, Cardozo, Castro-Diaz, Cornu, Deprest, Gunnemann, Gyhagen, Heesakkers, Koelbl, MacNeil, Naumann, Roovers, Salvatore, Sievert, Tarcan, Van der Aa, Montorsi, Wirth, Abdel-Fattah. Critical revision of the manuscript for important intellectual content: Chapple, Cruz, Deffieux, Milani, Arlandis, Artibani, Bauer, Burkhard, Cardozo, Castro-Diaz, Cornu, Deprest, Gunnemann, Gyhagen, Heesakkers, Koelbl, MacNeil, Naumann, Roovers, Salvatore, Sievert, Tarcan, Van der Aa, Montorsi, Wirth, Abdel-Fattah.

Statistical analysis: None.

Obtaining funding: None.

Administrative, technical, or material support: None.

Supervision: None.

Other: None.

Financial disclosures: Christopher Ronald Chapple certifies that all conflicts of interest, including specific financial interests and relationships and affiliations relevant to the subject matter or materials discussed in the manuscript (eg, employment/affiliation, grants or funding, consultancies, honoraria, stock ownership or options, expert testimony, royalties, or patents filed, received, or pending), are the following: Mohamed Abdel-Fattah: past speaker for Bard, Coloplast, 
AMS, Pfizer, and Astellas; research grant from Coloplast; previous chairman of the Scottish Pelvic Network, sponsored by various industrial companies. Salvador Arlandis: researcher for Astellas, Coloplast, and Ipsen; speaker and consultant for Astellas, Pfizer, Gebro, and Medtronic. Ricarda Bauer: consultant, speaker, and researcher for Boston Scientific and Promedon. Fiona Burkhard: speaker for Allergan and consultant for Novartis. Linda Cardozo: Allergan, Astellas, BMR, Pfizer, Pierre-Fabre, and Syner-Med. David Castro Diaz: speaker for Astellas, Gebro, and Recordati; investigator for Astellas, Allergan, and Ipsen. Christopher Chapple: consultant, speaker, and researcher for Allergan, Astellas, Boston Scientific, Medtronic, and Recordati. Jean Nicolas Cornu: consultant for Boston Scientific, Coloplast, EDAP-TMS, Bouchara Recordati, Bard, Astellas, Pfizer, Takeda, and Allergan; researcher for GSK, Coloplast, Allergan, and Cousin Biotech. Francisco Cruz: speaker, consultant, and investigator for Allergan, Astellas, AMS, Ipsen, Recordati, and Pfizer. Xavier Deffieux: consultant and speaker for Allergan and B-Braun. Jan Deprest: consultant for AMS, Ethicon, Bard, and Coloplast; researcher for Ethicon, Garrard and Blasingame Lawyers, and Clayton Law. Alfons Gunnemann: speaker for Janssen, Coloplast, and Bayer. Maria Gyhagen: speaker for Astellas. John Heesakkers: consultant for Pierre Fabre, Astellas, and Bluewind; speaker for Astellas, Allergan, Pierr Fabre, Boston and Scientific Int; research grants from Astellas, Allergan, Boston Scientific, and Urogyn BV. Jan-Paul Roovers: researcher for Coloplast, Tepha, Urogyn, and AMI; consultant for Coloplast and Tepha; speaker for Astellas and Cogentix. Stefano Salvatore: researcher for Astellas, Italfarmaco, Cynosure, and Shionogi; consultant and speaker for Astellas, Allergen, Deka, Fidia, Shionogi, and Coloplast. Frank Van der Aa: speaker for Astellas, GSK, and Ipsen; investigator (unrestricted grants) for Astellas, Allergan, and Medtronic. Walter Artibani, Heinz Koelbl, Sheila MacNeil, Alberto Milani, Gert Naumann, Karl-Dietrich Sievert, and Tufan Tarcan: nothing to disclose.

Funding/Support and role of the sponsor: None.

Acknowledgements: This paper has also been influenced by discussions during the meetings of the European Cooperation in Science and Technology (COST) Biomedicine and Molecular Biosciences Action BM1209 Regenerative Sphincter Therapy, funded by the European Commission.

\section{References}

[1] Slieker-ten Hove MCP, Pool-Goudzwaard AL, Eijkemans MJ, Steegers-Theunissen RP, Burger CW, Vierhout ME. Symptomatic pelvic organ prolapse and possible risk factors in a general population. Am J Obstet Gynecol 2009;200:184.e1-7.

[2] Gyhagen M, Bullarbo M, Nielsen TF, Milsom I. Prevalence and risk factors for pelvic organ prolapse 20 years after childbirth: a national cohort study in singleton primiparae after vaginal or caesarean delivery. BJOG 2013;120:152-60.

[3] de Boer TA, Slieker-Ten Hove MC, Burger CW, Kluivers KB, Vierhout ME. The prevalence and factors associated with previous surgery for pelvic organ prolapse and/or urinary incontinence in a cross-sectional study in The Netherlands. Eur J Obstet Gynecol Reprod Biol 2011;158:343-9.

[4] Smith AR, Koelbl H. Is mid-urethral placement of synthetic minimal access tapes important in stress urinary incontinence surgery? Neurourol Urodyn 2010;29(4):676-8.

[5] Hannestad YS, Rortveit G, Sandvik H, et al. A community-based epidemiological survey of female urinary incontinence: the Norwegian EPINCONT study. Epidemiology of Incontinence in the County of Nord-Trøndelag. J Clin Epidemiol 2000;53:1150-7.

[6] Glazener C, Elders A, Macarthur C, et al. Childbirth and prolapse: long-term associations with the symptoms and objective measurement of pelvic organ prolapse. BJOG 2013;120:161-8.
[7] Gutman RE, Ford DE, Quiroz LH, Shippey SH, Handa VL, et al. Is there a pelvic organ prolapse threshold that predicts pelvic floor symptoms? Am J Obstet Gynecol 2008;199:683.e1-7.

[8] Abdel-Fattah M, Familusi A, Fielding S, Ford J, Bhattacharya S. Primary and repeat surgical treatment for female pelvic organ prolapse and incontinence in parous women in the UK: a register linkage study. BMJ Open 2011;1:e000206.

[9] Denman MA, Gregory WT, Boyles SH, Smith V, Edwards SR, Clark AL. Reoperation 10 years after surgically managed pelvic organ prolapse and urinary incontinence. Am J Obstet Gynecol 2008;198:555.e1-5.

[10] Ficarra V, Novara G, Rosen RC, et al. Systematic review and metaanalysis of studies reporting urinary continence recovery after robot-assisted radical prostatectomy. Eur Urol 2012;62:405-17.

[11] Labrie J, Berghmans BL, Fischer K, et al. Surgery versus physiotherapy for stress urinary incontinence. N Engl J Med 2013;369: 1124-33.

[12] Lapitan MCM, Cody JD. Open retropubic colposuspension for urinary incontinence in women. Cochrane Database Syst Rev 2016;2:CD002912.

[13] Dean N, Ellis G, Wilson PD, Herbison GP. Laparoscopic colposuspension for urinary incontinence in women. Cochrane Database Syst Rev 2006;3:CD002239.

[14] Maher C, Feiner B, Baessler K, Christmann-Schmid C, Haya N, Brown J. Surgery for women with anterior compartment prolapse. Cochrane Database Syst Rev 2016;11:CD004014.

[15] Novara G, Artibani W, Barber MD, et al. Updated systematic review and meta-analysis of the comparative data on colposuspensions, pubovaginal slings and midurethral tapes in the surgical treatment of female stress urinary incontinence. Eur Urol 2010;58:218-38.

[16] Glazener CM, Cooper K. Bladder neck needle suspension for urinary incontinence in women. Cochrane Database Syst Rev 2014;12: CD003636.

[17] Rehman H, Bezerra CC, Bruschini H, Cody JD. Traditional suburethral sling operations for urinary incontinence in women. Cochrane Database Syst Rev 2011;1:CD001754.

[18] Albo ME, Richter HE, Brubaker L, et al. Burch colposuspension versus fascial sling to reduce urinary stress incontinence. N Engl J Med 2007;356:2143-55.

[19] Khan N, Abboudi H, Khan MS, Dasgupta P, Ahmed K. Measuring the surgical "learning curve": methods, variables and competency. BJU Int 2014;113:504-8.

[20] Ford AA, Rogerson L, Cody JD, Ogah J. Mid-urethral sling operations for stress urinary incontinence in women. Cochrane Database Syst Rev 2015;7:CD006375.

[21] SCENIHR. Final opinion on the safety of surgical meshes used in urogynecological surgery; 2015. http://ec.europa.eu/health/ scientific_committees/emerging/docs/scenihr_0_049.pdf.

[22] Karmakar D, Mostafa A, Abdel-Fattah M. Long-term outcomes of transobturator tapes in women with stress urinary incontinence; ETOT randomised controlled trial. BJOG. In press. http://dx.doi.org/ 10.1111/1471-0528.14561.

[23] Ulrich D, Tammaa A, Hölbfer S, et al. Ten-year followup after tension-free vaginal tape-obturator procedure for stress urinary incontinence. J Urol 2016;196:1201-6.

[24] Serati M, Braga A, Athanasiou S, et al. Tension-free vaginal tapeobturator for treatment of pure urodynamic stress urinary incontinence: efficacy and adverse effects at 10-year follow-up. Eur Urol 2017;71:674-9.

[25] European Association of Urology. EAU guidelines on urinary incontinence in adults. 2016 In: https://uroweb.org/wp-content/ uploads/EAU-Guidelines-Urinary-Incontinence-2016.pdf.

[26] Mostafa A, Lim CP, Hopper L, Madhuvrata P, Abdel-Fattah M. Singleincision mini-slings versus standard midurethral slings in surgical 
management of female stress urinary incontinence: an updated systematic review and meta-analysis of effectiveness and complications. Eur Urol 2014;65:402-27.

[27] Pickard R, Reaper J, Wyness L, Cody DJ, McClinton S, N'Dow J. Periurethral injection therapy for urinary incontinence in women. Cochrane Database Syst Rev 2003;2:CD003881.

[28] Aref-Adib M, Lamb BW, Lee HB, et al. Stem cell therapy for stress urinary incontinence: a systematic review in human subjects. Arch Gynecol Obstet 2013;288:1213-21.

[29] Biardeau X, Aharony S, AUS Consensus Group. Campeau L, Corcos J. Overview of the 2015 ICS Consensus Conference. Neurourol Urodyn 2016;35(4):437-43.

[30] Lucas MG, Bosch RJL, Burkhard FC, et al. Guía clínica de la Asociación Europea de Urología sobre el tratamiento quirúrgico de la incontinencia urinaria. Acta Urol Esp 2013;37:459-72.

[31] Fritel X, Fauconnier A, Bader G, et al. Diagnosis and management of adult female stress urinary incontinence: guidelines for clinical practice from the French College of Gynaecologists and Obstetricians. Eur J Obstet Gynecol Reprod Biol 2010;151:14-9.

[32] Hermieu J-F, Conquy $S$, Leriche $B$, et al. Synthèse des recommandations pour le traitement de l'incontinence urinaire féminine non neurologique. Prog Urol 2010;20:S94-9.

[33] Miedel A, Ek M, Tegerstedt G, Mæhle-Schmidt M, Nyrén O, Hammarström M. Short-term natural history in women with symptoms indicative of pelvic organ prolapse. Int Urogynecol J 2011;22:461-8.

[34] Bradley CS, Zimmerman MB, Qi Y, Nygaard IE. Natural history of pelvic organ prolapse in postmenopausal women. Obstet Gynecol 2007;109:848-54.

[35] Ismail SI, Bain C, Hagen S. Oestrogens for treatment or prevention of pelvic organ prolapse in postmenopausal women. Cochrane Database Syst Rev 2010;9:CD007063.

[36] Hagen S, Stark D, Glazener C, et al. Individualised pelvic floor muscle training in women with pelvic organ prolapse (POPPY): a multicentre randomised controlled trial. Lancet 2014;383:796-806.

[37] Bugge C, Adams EJ, Gopinath D, Reid F. Pessaries (mechanical devices) for pelvic organ prolapse in women. Cochrane Database Syst Rev 2013;2:CD004010.

[38] Chmielewski L, Walters MD, Weber AM, Barber MD. Reanalysis of a randomized trial of 3 techniques of anterior colporrhaphy using clinically relevant definitions of success. Am J Obstet Gynecol 2011;205:69.e1-8.

[39] Kapoor DS, Nemcova M, Pantazis K, Brockman P, Bombieri L, Freeman RM. Reoperation rate for traditional anterior vaginal repair: analysis of 207 cases with a median 4-year follow-up. Int Urogynecol J 2010;21:27-31.

[40] Maher C, Feiner B, Baessler K, Christmann-Schmid C, Haya N, Brown J. Surgery for women with apical vaginal prolapse. Cochrane Database Syst Rev 2016;10:CD012376.

[41] Glazener CM, Breeman S, Elders A, et al. Mesh, graft, or standard repair for women having primary transvaginal anterior or posterior compartment prolapse surgery: two parallel-group, multicentre, randomised, controlled trials (PROSPECT). Lancet 2017;389:381-92.

[42] Maher C, Feiner B, Baessler K, Schmid C. Surgical management of pelvic organ prolapse in women. Cochrane Database Syst Rev 2013;4:CD004014.
[43] Visco AG, Advincula AP. Robotic gynecologic surgery. Obstet Gynecol 2008;112:1369-84.

[44] Mueller MG, Ellimootil C, Abernethy MG, Mueller ER, Hohmann S, Kenton K. Colpocleisis: a safe, minimally invasive option for pelvic organ prolapse. Female Pelvic Med Reconstr Surg 2015;21:30-3.

[45] Vij M, Bombieri L, Dua A, Freeman R. Long-term follow-up after colpocleisis: regret, bowel, and bladder function. Int Urogynecol J 2014;25:811-5.

[46] Zebede S, Smith AL, Plowright LN, Hegde A, Aguilar VC, Davila GW. Obliterative LeFort colpocleisis in a large group of elderly women. Obstet Gynecol 2013;121(2 Part 1):279-84.

[47] Smith DB, Smith DB, Kelsey JF, et al. Laparoscopic uterine suspension. J Reprod Med 1977;18:98-102.

[48] Poulhés J, Rieu JP, Becue J. Strip of skin for uterine suspension and vesical support. J Chir 1971;101:563-70.

[49] Ridley JH. A composite vaginal vault suspension using fascia lata. Am J Obstet Gynecol 1976;126:590-6.

[50] Ostrzenski A. Laparoscopic colposuspension for total vaginal prolapse. Int J Gynaecol Obstet 1996;55:147-52.

[51] Filmar GA, Fisher HW, Aranda E, Lotze PM. Laparoscopic uterosacral ligament suspension and sacral colpopexy: results and complications. Int Urogynecol J 2014;25:1645-53.

[52] Cunjian Y, Li L, Xiaowen W, Shengrong L, Hao X, Xiangqiong L. A retrospective analysis of the effectiveness of a modified abdominal high uterosacral colpopexy in the treatment of uterine prolapse. Cell Biochem Biophys 2012;64:95-9.

[53] Lowenstein L, Fitz A, Kenton K, FitzGerald MP, Mueller ER, Brubaker L. Transabdominal uterosacral suspension: outcomes and complications. Am J Obstet Gynecol 2009;200:656.e1-5.

[54] Crigler B, Zakaria M, Hart S. Total laparoscopic hysterectomy with laparoscopic uterosacral ligament suspension for the treatment of apical pelvic organ prolapse. Surg Technol Int 2012;22:195-202.

[55] Jeon MJ, Jung HJ, Choi HJ, Kim SK, Bai SW. Is hysterectomy or the use of graft necessary for the reconstructive surgery for uterine prolapse? Int Urogynecol J 2008;19:351-5.

[56] Amid PK. Classification of biomaterials and their related complications in abdominal wall hernia surgery. Hernia 1997;1:15-21.

[57] Jones R, Abrams P, Hilton P, Ward K, Drake M. Risk of tape-related complications after TVT is at least 4\%. Neurourol Urodyn 2010;29:40-1.

[58] Abrams P, Shearer K. The MASTER trial: artificial urinary sphincter versus male sling. Trends Urol Mens Health 2015;6:37-8.

[59] Slack M, Ostergard D, Cervigni M, Deprest J. A standardized description of graft-containing meshes and recommended steps before the introduction of medical devices for prolapse surgery. Consensus of the 2nd IUGA Grafts Roundtable: optimizing safety and appropriateness of graft use in transvaginal pelvic reconstructive surgery. Int Urogynecol J 2012;23(Suppl 1):S15-26.

[60] Davila GW, Baessler K, Cosson M, Cardozo L. Selection of patients in whom vaginal graft use may be appropriate. Consensus of the 2 nd IUGA Grafts Roundtable: optimizing safety and appropriateness of graft use in transvaginal pelvic reconstructive surgery. Int Urogynecol J 2012;23(Suppl 1):S7-14. 